\title{
Determinants of Categories of TB Retreatment with Special Reference to Sources of Primary Anti-TB Treatment
}

\author{
Veerabadran Karthikeyan ${ }^{1}$ Kalaiselvan Ganapathy² \\ ${ }^{1}$ Department of Community Medicine, Government Tiruvannamalai \\ Medical College and Hospital, Tiruvannamalai, Tamil Nadu, India \\ 2Department of Community Medicine, Sri Manakula Vinayagar \\ Medical College and Hospital, Puducherry, India
}

\begin{abstract}
Address for correspondence Kalaiselvan Ganapathy, MD, Department of Community Medicine, Sri Manakula Vinayagar Medical College and Hospital, Puducherry 605107, India (e-mail: kalaiselvanmd@gmail.com).
\end{abstract}

J Health Allied Sci ${ }^{\mathrm{NU}}: 2020 ; 10: 116-121$

\begin{abstract}
Keywords

- previously treated

- retreatment

- sources of previous treatment

- tuberculosis

Introduction Retreatment (previously treated) cases are the tuberculosis (TB) patients who have been treated previously with anti-TB drugs for at least a month and who have now been registered for category II anti-TB therapy. Retreatment cases arise due to inadequate and improper treatment of the new TB cases.

Objective The aim of the study is to assess the information regarding sources of previous TB drug exposure and treatment practices leading to retreatment cases (category II) and determinants leading to retreatment.

Material and Methods It was a community-based cross-sectional study of patients registered as retreatment TB cases under revised national TB control program (RNTCP) in the TB unit of Puducherry between October 2013 and September 2014. The study was held between October 2013 and October 2015. Initially the quantitative data were collected and followed by qualitative data. Data were collected by interviewing the patients using a predesigned questionnaire. Data were entered and analyzed by using Epi Info (Version 3.4.3) software package.

Results Out of the 193 study participants, relapse cases were the most common $50.8 \%$, followed by treatment after default cases $23.8 \%$, failure cases $11.9 \%$, and retreatment others $13.5 \%$. There is a significant association between the retreatment categories such as failure, TAD (treatment after default), retreatment others, and ever usage of tobacco $(p<0.05)$. There is also a significant association between the retreatment categories such as TAD, retreatment others, and ever usage of alcohol $(p<0.05)$. The sources of previous antitubercular therapy for $90.16 \%$ retreatment cases were from government health care facilities under RNTCP, whereas for $9.84 \%$ retreatment cases the sources of previous antitubercular treatment were private health care facilities. There is a significant association between public health care facility where patients were previously treated for TB and relapse $(p=0.001)$ and private health care facility where patients were previously treated for TB and TAD $(p=0.008)$.

Conclusion As $90 \%$ of the patients have utilized the government health services for treatment, it shows the effective functioning of RNTCP-STF (state task force-revised national TB control program) mechanism in Puducherry.
\end{abstract}




\section{Introduction}

Tuberculosis (TB) remains as one of the major public health problems; it was one of the top ten causes of death worldwide in 2015. The STOP TB strategy was developed by World Health Organization (WHO) with the goal of reducing the global burden of TB by 2015 in line with the millennium development goals. One of the principal components of STOP-TB strategy is addressing the multidrug-resistance TB cases (MDR-TB), which is a threat to global TB control. ${ }^{1}$ In South East Asian Region, retreatment TB cases account for $16 \%$ of MDR-TB cases, which in turn account for $30 \%$ of world's MDR-TB cases in 2013. ${ }^{2}$ Retreatment TB (previously treated) cases are the TB patients who have been treated previously with anti-TB drugs for at least a month and who have now been registered for category II anti-TB therapy. Retreatment cases arise due to inadequate and improper treatment of the new TB cases. ${ }^{3,4}$

Newly diagnosed TB patients seek care from a wide range of private health care providers apart from public sector. These private health care providers may serve a large population of TB suspects and TB patients, but they may not always follow recommended treatment practices or reporting mechanisms. ${ }^{5}$ Failure to engage all these health care providers causes inappropriate and incomplete treatment, increases drug resistance, and places a huge unnecessary financial burden on patients. WHO has released its post-2015 Global TB strategy called "End TB strategy" which aims to eliminate TB by 2035. It is important to know the sources of previous TB drug exposure for patients registered as retreatment tuberculosis which is also one of the agenda for operational research under revised national TB control program (RNTCP). ${ }^{6}$ Hence our objective was to assess the information regarding sources of previous TB drug exposure and treatment practices leading to retreatment cases (category II) and to find the determinants leading to retreatment.

\section{Materials and Methods}

\section{Study Area and Setting}

The study was performed in the urban and rural localities of Puducherry district which comes under the State Tuberculosis Unit (TU) of Puducherry Union Territory. The study area is spread over a radius of $25 \mathrm{~km}$. The Chest clinic as well as State TU is situated in the heart of the city and functions as a core of the Revised National Tuberculosis Control Program covering the urban and the rural population of Puducherry district. The present study was undertaken by the Department of Community Medicine, Sri Manakula Vinayagar Medical College and Hospital, Puducherry, which is an active member in STF-RNTCP (state task force-revised national TB control program) mechanism.

\section{Study Design}

An exploratory sequential design where quantitative methods (community-based cross sectional survey) followed by qualitative methods (Free listing) was used.

\section{Sample Size and Sampling \\ Quantitative Method}

All the patients registered as retreatment TB cases under RNTCP in the TU of Puducherry between October 2013 and September 2014 were invited to participate in the study. Out of the 209 retreatment cases registered for treatment during this period, ten cases expired and six cases were excluded from the study because of the reasons such as refusal to give consent, shifted to new place or defaulted again. Finally 193 retreatment cases were recruited for the study.

\section{Qualitative Method}

A sample of four category-two patients and two TB health visitors were purposely selected. All the participants were literate. These patients were asked to list out the (free list) the reasons for the previous treatment exposure. The TB health visitors (TBHVs) were asked to list out the common reasons told to them by the patients during their DOTS treatment. This method was used as it was convenient and less time consuming. The free listing was conducted in local language by the principal investigator who is trained in qualitative research methods. The process was stopped at saturation point when no new information received.

\section{Data Collection}

The quantitative study was conducted from October 2013 to September 2014, while qualitative study was continued up to 2015 . A predesigned questionnaire was pilot tested among 20 retreatment cases to check the wording and the appropriateness of the questions in the questionnaire. The questionnaire used in this study included three parts. First part included details regarding socio-demographic characteristics of the respondent. Housing, environmental conditions, personal habits such as smoking and alcohol history were also enquired in this part. The second part of the questionnaire included details regarding knowledge, attitude, and practices of the respondents regarding TB. The third part of the questionnaire included details of previous TB treatment. After obtaining permission from the concerned primary health centers (PHC)/community health centers (CHCs) Medical Officers, interview sessions were arranged with the help of the concerned TB health visitor. After obtaining informed consent from the respondent, the questionnaire was administered and data were collected.

\section{Data Analysis}

Data were entered and analyzed using Epi Info (Version 3.4.3) software package. Descriptive statistics such as frequency, percentage, and mean were used to analyze the sociodemographic details, source of previous treatment, retreatment categories, current knowledge about TB, and co-morbidities. Chi-square test $\left(\chi^{2}\right)$ (Fischer exact test was used for cells with values less than 5) was used to assess the association between retreatment categories and sociodemographic details, sources of previous treatment, etc. The manual content analysis of qualitative data was done by the co-investigator. 


\section{Ethical Issues}

Ethical principles such as respect for the persons, beneficence, and justice were adhered. Ethical clearance was obtained from the Research Committee and Institutional Ethics Committee of Sri Manakula Vinayagar Medical College and Hospital, Madagadipet, Puducherry.

\section{Results}

In our study, majority of the retreatment cases $82.9 \%$ were male and $17.1 \%$ were female. Majority of the study participants $52.8 \%$ were in the age group 36 to 55 years. The mean age of the male respondents $46.91( \pm 12.47)$ was significantly higher than that of female $37.39( \pm 17.75)(p<0.05)$. Most of them $62.7 \%$ were residing in urban area. About $52.3 \%$ were belonging to below poverty line. About $90.2 \%$ of the study participants were literate and $9.8 \%$ were illiterate. Among the study participants approximately $22.8 \%$ were unemployed. Among the currently employed $43.5 \%$ were laborers by occupation.

- Table 1 mentions the determinants for the retreatment cases, out of the 193 retreatment cases $65.3 \%$ reported ever usage of tobacco whereas, current usage of tobacco was reported by $23.3 \%$ of study participants. Among both ever users and current users, smoking form of tobacco was reported to be most commonly used by 80.2 and $86.7 \%$ study participants, respectively. Ever usage of alcohol was reported by $61.7 \%$ study participants, whereas $21.2 \%$ study participants reported current usage of alcohol. Lack of adequately ventilated house was reported by $48.7 \%$ and lack of cross ventilation was reported by $60.6 \%$. About $81.3 \%$ were diagnosed with having TB during their previous treatment from government health care facility, whereas $17.1 \%$ were diagnosed by private health care providers. About $1.6 \%$ study participants were not able to recall about the place of diagnosis. The source of previous antitubercular therapy for $90.16 \%$ retreatment cases was from government health care facilities under RNTCP, whereas for $9.84 \%$ retreatment cases, the source of previous antitubercular treatment was private health care facilities. Overall, the ever usage of tobacco, alcohol usage, and noncompliance to the treatment were more common among male which was statistically significant.

- Table 2 shows the significant association between the retreatment categories such as failure, TAD, retreatment others, and ever usage of tobacco $(p<0.05)$. There is also a significant association between the retreatment categories such as TAD, retreatment others, and ever usage of alcohol $(p<0.05)$, and also between health care facility where previously treated for TB and relapse $(p=0.001)$. There is also association between cross-ventilation and other category of retreatment $(p=0.01)$.

As mentioned in - Table 3, the categories emerged from the free listings of the TB patients are: (1) side effects of anti-TB drugs, (2) too many drugs/long duration of treatment, (3) Loss of job/inability to work, and (4) lack of adequate knowledge. The categories emerged from TBHV are (1) addiction, (2) supervision and monitoring related issues, (3) poor support from family, stigma, and (4) lack of adequate knowledge.

Table 1 Distribution of retreatment cases by determinants of retreatment category

\begin{tabular}{|c|c|c|c|c|}
\hline Variable & Male $n=160$ & Female $n=33$ & Total $n=193$ & $\chi^{2}, \mathrm{df}, p$-value \\
\hline \multicolumn{5}{|l|}{ Tobacco ever usage } \\
\hline Yes & $121(75.6)$ & $5(15.2)$ & $126(65.3)$ & \multirow[t]{2}{*}{$43.92(0.001)$} \\
\hline No & $39(24.4)$ & $28(84.8)$ & $67(34.7)$ & \\
\hline \multicolumn{5}{|l|}{ Alcohol ever usage } \\
\hline Yes & $118(73.8)$ & $1(3)$ & $119(61.7)$ & \multirow[t]{2}{*}{$57.58(0.001)$} \\
\hline No & $42(26.2)$ & $32(97)$ & $74(38.3)$ & \\
\hline \multicolumn{5}{|l|}{ Place where first diagnosed } \\
\hline Government health care facility & 147(91.9) & $26(78.8)$ & $174(90.1)$ & \multirow[t]{2}{*}{$3.42,1,(0.06)$} \\
\hline Private health facility & $13(8.1)$ & $6(18.2)$ & $19(9.9)$ & \\
\hline \multicolumn{5}{|l|}{ Previous knowledge of TB } \\
\hline Yes & $140(87.5)$ & $26(78.8)$ & $166(89.1)$ & \multirow[t]{2}{*}{$0.215(0.642)$} \\
\hline No & $20(12.5)$ & $7(21.2)$ & $27(10.9)$ & \\
\hline \multicolumn{5}{|l|}{ Supervision } \\
\hline Yes & $137(85.6)$ & $23(69.6)$ & $160(86)$ & \multirow[t]{2}{*}{$0.969(0.324)$} \\
\hline No & $23(14.4)$ & $10(30.3)$ & $33(14)$ & \\
\hline \multicolumn{5}{|l|}{ Compliance } \\
\hline Compliance & $104(65)$ & $29(87.8)$ & $133(69)$ & \multirow[t]{2}{*}{$6.65(0.001)$} \\
\hline Noncompliance & $56(35)$ & $4(12.2)$ & $60(31)$ & \\
\hline
\end{tabular}

Note: Figures in parenthesis are percentages. 
Table 2 Association of retreatment category with ventilation, Government health care facility, ever used tobacco and alcohol usage

\begin{tabular}{|c|c|c|c|}
\hline Retreatment category & Ventilation adequate $n=98$ & Ventilation inadequate $n=95$ & $p$-Value ( $X^{2}$ test) \\
\hline Relapse & $52(53.1)$ & $46(48.5)$ & 0.51 \\
\hline Failure & $11(11.2)$ & $12(12.6)$ & 0.76 \\
\hline TAD & $19(19.4)$ & $27(28.4)$ & 0.14 \\
\hline Others & $16(16.3)$ & $10(10.5)$ & 0.23 \\
\hline Retreatment category & Cross ventilation present $n=77$ & No cross ventilation $n=116$ & \\
\hline Relapse & $38(49.3)$ & $60(51.7)$ & 0.74 \\
\hline Failure & $8(10.4)$ & $15(13.0)$ & 0.59 \\
\hline TAD & $15(19.5)$ & $31(26.7)$ & 0.24 \\
\hline Others & $16(20.8)$ & $10(8.6)$ & 0.01 \\
\hline Retreatment category & Government health care facility $n=174$ & Private health care facility $n=19$ & \\
\hline Relapse & $95(54.6)$ & $3(15.8)$ & 0.001 \\
\hline Failure & $22(12.7)$ & $1(5.3)$ & 0.611 \\
\hline TAD & $36(20.7)$ & $10(52.6)$ & 0.008 \\
\hline Others & $21(12)$ & $5(26.3)$ & 0.182 \\
\hline Retreatment category & Ever used tobacco: yes $(n=126)$ & Ever used tobacco: no $(n=67)$ & \\
\hline Relapse & $60(47.6)$ & $38(56.7)$ & 0.229 \\
\hline Failure & $20(15.9)$ & $3(4.5)$ & 0.020 \\
\hline TAD & $38(30.2)$ & $8(11.9)$ & 0.004 \\
\hline Others & $8(6.3)$ & $18(26.9)$ & 0.0001 \\
\hline Retreatment category & Ever used alcohol: yes $(n=119)$ & Ever used alcohol: no $(n=74)$ & \\
\hline Relapse & $59(49.6)$ & $39(52.7)$ & 0.67 \\
\hline Failure & $17(14.3)$ & $6(8.1)$ & 0.19 \\
\hline TAD & $36(30.2)$ & $10(13.5)$ & 0.007 \\
\hline Others & $7(5.9)$ & $19(25.7)$ & 0.0001 \\
\hline
\end{tabular}

Abbreviation: TAD, treatment after default.

Note: Figures in parenthesis are percentages.

\section{Discussion}

In the present study, majority of the retreatment cases were male $82.9 \%$. Majority of the study participants $52.8 \%$ were in the age group 36 to 55 years. The study conducted by Sarpal et $\mathrm{al}^{7}$ in Chandigarh, shows similar findings as our present study with respect to gender and age. As per the census 2011 data, Pondicherry has an average literacy rate of $85.85 \%$, higher than the national average of $74 \% .^{8,9}$ In our study $90.2 \%$ of the study participants were literate and $9.8 \%$ were illiterate. Among the study participants approximately $22.8 \%$ were unemployed.

Present study shows that, there is a significant association between the retreatment categories such as failure, TAD, retreatment others, and ever usage of tobacco $(p<0.05)$. There is also a significant association between the retreatment categories such as TAD, retreatment others and ever usage of alcohol $(p<0.05)$. Similarly the study conducted by Dooley et al in Morocco shows that substance use appeared to be a risk factor for default. ${ }^{10}$ The study conducted by Thomas et al in Thiruvallur district, Tamil Nadu shows that smoking is a risk factor for relapse and relapse rate could be effectively reduced by effective counseling about quitting smoking. ${ }^{11}$ Similarly the study conducted in West Bengal also reported similar findings. ${ }^{12}$ This study was conducted in 20 districts of six states and have reported that even though smoking and alcohol were associated with default, but they were specific to few regions only. ${ }^{13}$

The findings of the present study show that, the source of previous antitubercular therapy for $90.16 \%$ retreatment cases was from government health care facilities under RNTCP. Among those who obtained previous antitubercular therapy from government health care facility, most of them (78.7\%) obtained antitubercular therapy from PHCs, CHCs, and health subcenters. The union territory of Puducherry has five tertiary care level hospitals, two CHCs, 12 urban, and 15 rural PHCs, 14 urban and 35 rural subcenters. Majority of the people in Puducherry utilize the government health services; this was supported by the findings of study conducted by Prasad et al. ${ }^{14}$ Another study conducted in Puducherry has also reported similar finding. ${ }^{15}$ The reason could be due to successful involvement of Medical Colleges through State Task Force Mechanism. But the study conducted in 2011 by Sachdeva et al has reported that more than half of the retreatment cases had treatment from non-RNTCP sources. ${ }^{16}$ 
Table 3 Free listing among four retreatment patients and two TBHV

\begin{tabular}{|c|c|}
\hline Patients & TBHV \\
\hline Side effects of anti-TB drugs & Addiction \\
\hline Severe vomiting & Chronic alcoholism: not able to quit alcohol \\
\hline Abdominal pain & Unsuccessful quit attempts \\
\hline Burning sensation in stomach & Tobacco usage, smoking \\
\hline Developed jaundice & Supervision and monitoring-related issues \\
\hline Generalized weakness & Could not retrieve the patients' address \\
\hline Easy fatigability & Wrong address given \\
\hline Drowsiness & Patient has migrated to new place \\
\hline Too many drugs/Long duration of treatment & Patients house remains always locked \\
\hline Has to take many tablets per day & Poor support from family \\
\hline $\begin{array}{l}\text { Very long duration of treatment which interferes with normal life } \\
\text { functions. }\end{array}$ & $\begin{array}{l}\text { Other family problems like living alone, broken family, widow or } \\
\text { widower, elderly dependent person. }\end{array}$ \\
\hline Loss of job/Inability to work & Lack of support from the family \\
\hline Cannot resume to job after taking the drug & Stigma \\
\hline Cannot do heavy work because of side effects & Social stigma still prevails \\
\hline Feel very weak to carry out the job & Lack of adequate knowledge \\
\hline Feeling weak after taking tablets, so could not work & Illiteracy, discontinues treatment as health improves \\
\hline Lack of adequate knowledge & Carelessness about their health \\
\hline $\begin{array}{l}\text { Felt that health has improved after taking treatment for few weeks } \\
\text { so discontinued treatment. }\end{array}$ & Uncooperative patients threatening TBHV for visiting their home. \\
\hline Felt healthy after intensive phase. & Depression \\
\hline Attained sputum smear negative after intensive phase & $\begin{array}{l}\text { Feeling mentally week because of the disease and side effects of } \\
\text { treatment }\end{array}$ \\
\hline $\begin{array}{l}\text { Adopted other modes of treatment-Homeopathy, Siddha, } \\
\text { Ayurveda }\end{array}$ & Economic problems \\
\hline Lack of faith in allopathy medicines & No active income, nonearning member in the family \\
\hline
\end{tabular}

Abbreviation: TBHV, tuberculosis health visitors.

In our study, $80.3 \%$ reported that they were supervised for adherence of treatment during their previous antitubercular treatment by government health facility staff. About $19.7 \%$ reported that they were not supervised for adherence during their previous treatment. This $19.7 \%$ constitutes those who have obtained their previous anti-TB treatment from private health care facility and those who obtained treatment from government health facility before 15 to 20 years. As per the "Treatment of Tuberculosis Guidelines" by WHO, supervised treatment helps the patients to take their TB medications regularly and to complete the TB treatment. ${ }^{3}$ It is also meant to ensure that the providers give proper care and are able to detect treatment interruption. Adherence to TB treatment is crucial to achieving cure while avoiding the emergence of drug resistance and also protects the community from the spread of TB.

In the present study, $66.3 \%$ reported that they have taken the drugs regularly and have completed the course of treatment during the previous treatment. About $33.7 \%$ reported that they have not taken the drugs regularly, failed to complete full course of treatment. The reasons for irregular treatment during the previous treatment reported by the study participants were (multiple responses) lack of knowledge and carelessness 50.7\%, long duration of treatment $33.8 \%$, too many drugs $33.8 \%$, side effects of the drugs $24.6 \%$, disturbance in day to day activities $24.6 \%$, does not improve with the drugs $0.5 \%$, shifted to new place $12.3 \%$, declared cured after intensive phase $3.0 \%$, alcohol dependence $10.7 \%$, felt health improved $9.2 \%$, and family issues $6.1 \%$. The reasons reported in our study for nonadherence of treatment are also reported in the other studies. ${ }^{13,15,17,18}$ To confirm further the qualitative exploration of the reasons for retreatment category yielded similar responses.

Present study shows that, there is a significant association between previous health care facility for TB and relapse $(p=0.001)$. Relapse was significantly more among those who got previously treated in government health care facility under RNTCP. TAD cases were found to be significantly higher among those who were previously treated in private health facilities. Similarly, the study conducted by Sachdeva et al also shows that "relapse" and "failure" cases are more likely to have been previously treated under RNTCP sources. ${ }^{16}$ 


\section{Conclusion}

As $90 \%$ of the patients have utilized the government health services for treatment, it shows the effective functioning of RNTCP-STF mechanism in Puducherry. Further, qualitative studies can enlighten the reasons for the nonadherence of treatment and reasons in previously treated cases.

\section{Funding}

The authors acknowledge the funding received from Chest clinic, Puducherry, under RNTCP financial assistance: MDPG thesis grant.

\section{Conflict of Interest}

None declared.

\section{References}

1 WorldHealthOrganization.ThestopTBstrategy;2006. Available at: http://apps.who.int/iris/bitstream/10665/69241/1/WHO_ HTM_STB_2006.368_eng.pdf. Accessed September 9, 2015

2 World Health Organization. Tuberculosis Control in South East Asia. Annual TB report 2015; 2015. Available at: http://www. searo.who.int/tb/annual-tb-report-2015.pdf. Accessed August 13,2015

3 World Health Organization. Treatment of tuberculosis guidelines. Available at: http://www.ncbi.nlm.nih.gov/books/ NBK138748/pdf/ Bookshelf_NBK138748.pdf. Accessed August 11,2015

4 RNTCP at a GLANCE. Central TB Division, Directorate General of Health Services, Ministry of Health and Family Welfare, Nirman Bhawan, New Delhi 110001. Available at: http://www. tbcindia.nic.in/pdfs/RNTCP\%20at\%20a\%20Glance.pdf

5 World Health Organization. Stop TB partnership. Publicprivate mix for TB care and control: A toolkit. 2010; Available at: http://www.who.int/tb/careproviders/ppm/PPMToolkit.pdf Accessed September 9, 2015

6 Operational Research Guidelines and Action Plan. Revised National Tuberculosis Control Program (RNTCP), India; 2009. Available at: http://www.tbcindia .org/pdfs/RNTCP\%20 Operational\% 20Research\%Guidelines\% 20 march\%202009.pdf. Accessed January 21, 2009
7 Sarpal SS, Goel NK, Kumar D, Janmeja AK. Gender disparities in retreatment patients of tuberculosis: a north Indian study. J Nat Sci Biol Med 2015;6(1):63-66

8 Puducherry profile. Census info India 2011. Final Population tables. Available at: http://censusindia.gov.in/2011census/ censusinfodashboard/stock/profiles/en/IND034_Pondicherry. pdf. Accessed September 2, 2015

9 Status of Literacy. Provisional Population Totals. Census of India 2011. Available at: http://Censusindia.Gov.In/2011-ProvResults/Data_Files/Mp/07literacy.Pdf. Accessed September 3, 2015

10 Dooley KE, Lahlou O, Ghali I, et al. Risk factors for tuberculosis treatment failure, default, or relapse and outcomes of retreatment in Morocco. BMC Public Health 2011;11(1):140

11 Thomas A, Gopi PG, Santha T, et al. Predictors of relapse among pulmonary tuberculosis patients treated in a DOTS programme in South India. Int J Tuberc Lung Dis 2005;9(5):556-561

12 Roy N, Basu M, Das S, Mandal A, Dutt D, Dasgupta S. Risk factors associated with default among tuberculosis patients in Darjeeling district of West Bengal, India. J Family Med Prim Care 2015;4(3):388-394

13 Vijay S, Kumar P, Chauhan LS, Vollepore BH, Kizhakkethil UP, Rao SG. Risk factors associated with default among new smear positive TB patients treated under DOTS in India. PLoS One 2010;5(4):e10043

14 Prasad KN, Ingalgeri BM, Poovitha R, et al. Utilization of health facilities at primary health centre by rural community of Pondicherry. IAIM 2015;2(2):71-76

15 Niranjjan R, Sahu SK, Roy G, Vani SAV. Source of previous anti-TB treatment for re-treatment TB cases registered under Revised National Tuberculosis Control Program in Pondicherry. Int J Community Med Publ Health 2017;4:3386-3393

16 Sachdeva KS, Satyanarayana S, Dewan PK, et al. Source of previous treatment for re-treatment TB cases registered under the National TB control Programme, India, 2010. PLoS One 2011;6(7):e22061

17 Patel KR, Patel A, Gadhiya NB. Risk Factors for sputum positive pulmonary tuberculosis retreatment cases and factors responsible for treatment outcome. J Assoc Physicians India 2019;67(8):56-58

18 Varshney AM, Singh US, Kumar D. Sources of Previous anti-tubercular drug exposure for patients registered in RNTCP as Retreatment cases in District Anand, Gujarat. Indian J Community Health 2013;25(2):159-163 